\title{
What are superintegrons?
}

\author{
Ruth M. Hall*, Andrew J. Holmes*, Paul H. Roy and H. W. Stokes ${ }^{\S}$ \\ *School of Molecular and Microbial Biosciences, University of Sydney, Sydney, 2006, NSW, Australia. \\ ${ }^{\ddagger}$ Centre de Recherche en Infectiologie and Département de Biochimie et de Microbiologie, Université \\ Laval, Quebec OC G1V 4G2, Canada. §Department of Chemistry and Biomolecular Sciences, Macquarie \\ University, Sydney, NSW, 2109, Australia. Correspondence to R.M.H. e-mail: \\ ruth.hall@mmb.usyd.edu.au
}

Although integrons have been found in transposons, in plasmids and in bacterial chromosomes, all integrons have the same basic properties, namely an intI gene and an attI site that allow them to capture gene cassettes ${ }^{1}$. When an integron is part of a transposon, as is the case for integron classes 1, 2 and probably 3 (REF. 2), it is obvious that this would vastly increase the capacity of the integron to capture cassettes from a wide range of bacterial sources. However, their location does not make them either structurally or functionally different from the more sedentary integrons found in bacterial genomes.

Mazel and co-workers initially noted that the integron in Vibrio cholerae N16961 was different to the integrons that had been described previously because it is found in the chromosome and had a large number (178) of cassettes associated with it, and they referred to it as a 'superintegron' (REF. 3). Subsequently, confusion arose because the term superintegron was applied to other integrons that were chromosomally located, even though most of these do not have a large cassette array. Defining a distinct type of integron based on arbitrary features of the cassette array is dangerous because the size and composition of the cassette array associated with an integron can easily change. This variability is necessarily intrinsic to a system that captures and harbours mobile elements, such as gene cassettes. These discrepancies were pointed out by Hall and Stokes ${ }^{1}$ who recommended that, as all integrons have the same basic properties, they should all be called integrons.

Despite this recommendation, a recent review ${ }^{4}$ continues to use, and re-defines, the term 'superintegron'. The three features that are now claimed to make superintegrons a 'distinct type' of integron are: first, that there are at least 20 cassettes in the associated array; second, that a single type (over $80 \%$ identical) of attC site (59-be) is predominantly found in these cassettes; andthird, that the integron is not associated with mobile elements ${ }^{4}$. However, in subsequent sections of the review, integrons that do not comply with this definition are also described as superintegrons.

So, what are superintegrons? This latest definition actually applies to only 3 of the integrons for which an analysis is available. The integrons so far found in the chromosomes of Vibrionaceae have more than 20 cassettes associated with them, but only in the case of $V$. cholerae is there a single sequence type for the 59-be $(a t t C)$ associated with the vast majority of these cassettes ${ }^{5,6}$. Among the remaining chromosomally located integrons for which an analysis of the cassette array has been published ${ }^{7-12}$, only 3 have over 20 cassettes (TABLE 1). Our analysis of these cassette arrays to determine if there is a single predominant 59-be type at the $80 \%$ identity level revealed that only the integrons in Xanthomonas campestris and Treponema denticola meet this criterion (TABLE 1). Therefore, based on currently available information, integrons with the features of a 'superintegron' are rather uncommon.

We continue to believe that the term superintegron is superfluous. The many definitions so far given and the lack of rigour in applying these definitions is creating unnecessary confusion. We recommend that all integrons, no matter what their location, remain simply integrons.

1. Hall, R. M. \& Stokes, H. W. Integrons or super integrons? Microbiology 150, 3-4 (2004).

2. Collis, C. M., Kim, M.-J., Partridge, S. R., Stokes, H. W. \& Hall, R. M. Characterization of the class 3 integron and the site-specific recombination system it determines. J. Bacteriol. 184, 3017-3026 (2002).

3. Mazel, D., Dychino, B., Webb, V.A. \& Davies, J. A distinctive class of integron in the Vibrio cholerae genome. Science 280, 605-608 (1998). 
4. Mazel, D. Integrons: agents of bacterial evolution. Nature Rev. Microbiol. 4, 608-620 (2006).

5. Boucher, Y. et al. Recovery and evolutionary analysis of complete integron gene cassette arrays from Vibrio. BMC Evol. Biol. 6, 3 (2006).

6. Rowe-Magnus, D. A., Guerout, A.-M., Biskri, L. Bouige, P. \& Mazel, D. Comparative analysis of superintegrons: Engineering extensive genetic diversity in the Vibrionaceae. Genome Res. 13, 428-442 (2003).

7. Vaisvila, R., Morgan, R. D., Posfai, J. \& Raleigh, E. A. Discovery and distribution of super-integrons amongst Pseudomonads. Mol. Microbiol. 42, 587-601 (2001).

8. Drouin, F., Melançon, J. \& Roy, P. H. The Intl-like tyrosine recombinase of Shewanella oneidensis is active as an integron integrase. J. Bacteriol. 184, 1811-1815 (2002).

9. Léon, G. \& Roy, P. H. Excision and integration of cassettes by an integron integrase of Nitrosomonas europaea. J. Bacteriol. 185, 2036-2041 (2003).

10. Gillings, M. R., Holley, M. P., Stokes, H. W. \& Holmes, A. J. Integrons in Xanthomonas: a source of genome diversity. Proc. Natl Acad. Sci. USA 102, 4419-4424 (2005).

11. Coleman, N., Tetu, S., Wilson, N. \& Holmes, A. J. An unusual integron in Treponema denticola. Microbiology 150, 3524-3526 (2004).

12. Holmes, A. J. et al. Recombination activity of a distinctive integron-gene cassette system associated with Pseudomonas stutzeri populations in soil. J. Bacteriol. 185, 918-928 (2003).

Table 1 | Properties of cassette arrays in analysed chromosomally located integrons

\begin{tabular}{|l|l|l|l|l|l|l|}
\hline Organism & Strain & $\begin{array}{l}\text { GenBank } \\
\text { accession } \\
\text { number }\end{array}$ & Intl & $\begin{array}{l}\text { Number of } \\
\text { cassettes* }\end{array}$ & $\begin{array}{l}\text { Single 59-be } \\
\text { type } \\
\text { predominant }^{\ddagger}\end{array}$ & $\begin{array}{l}\text { Super- } \\
\text { integron }\end{array}$ \\
\hline $\begin{array}{l}\text { Pseudomonas } \\
\text { alcaligenes }\end{array}$ & ATCC055044 & AY038186 & - & 32 (Ref. 7) & No $^{\S}$ & No \\
\hline $\begin{array}{l}\text { Shewanella } \\
\text { oneidensis }\end{array}$ & MR-1 & NC_004347 & SO_2039 & 3 (Ref. 8) & No & No \\
\hline $\begin{array}{l}\text { Nitrosomonas } \\
\text { europaea }\end{array}$ & ATCC19718 & NC_004757 & NE2189 & 1 (Ref. 9) & - & No \\
\hline $\begin{array}{l}\text { Treponema } \\
\text { denticola }\end{array}$ & ATCC35405 & NC_002967 & TDE1844 & 45 (Ref. 11) & Yes (Ref. 11) & Yes \\
\hline $\begin{array}{l}\text { Xanthomonas } \\
\text { campestris } \\
\text { pv. } \\
\text { campestris }\end{array}$ & ATCC33913 & NC_003902 & XCC0344 & 22 (Ref. 10) & Yes & Yes \\
\hline $\begin{array}{l}\text { Pseudomonas } \\
\text { stutzeri }\end{array}$ & Q & AY129392 & - & 10 (Ref. 12) & Yes & No \\
\hline $\begin{array}{l}\text { Pseudomonas } \\
\text { stutzeri }\end{array}$ & BAM17 & AY129393 & - & 14 (Ref. 12) & Yes & No \\
\hline
\end{tabular}

*The reference cited contains the published analysis of the number of cassettes in the array. References for the original genome sequences can be found through the GenBank entry. ${ }^{\ddagger}$ The similarity of 59 -be in the cassettes was analysed here. Predominant was taken to mean over $75 \%$ of the cassettes. ${ }^{\S} 16$ out of 32 cassettes have type 159 -be (average length $77 \mathrm{bp}$ ), 10 have type 259 -be (average length $89 \mathrm{bp).} \mathrm{"18} \mathrm{out} \mathrm{of} 22$ have the same 59 -be type (average length $60 \mathrm{bp}$ ). " 8 out of 10 and 12 out of 14 cassettes have the same type of 59 -be (average length $77 \mathrm{bp}$ ). Note this type is the same as type 1 from $P$. alcaligenes, indicating that 59-be types are not necessarily species specific. 